\title{
Use of Computer Simulations for the Understanding and Retention of Mathematical Concepts
}

\author{
Farkhunda Rasheed Choudhary ${ }^{1}$, Tariq Javed ${ }^{2}$
}

\begin{abstract}
Simulations provide unique features and instructional benefits for the improved understanding of concepts. This study aimed to find the effect of computer simulations on the understanding and retention of mathematical concepts. This was an experimental research. A sample of 100 students participated in this experimental research. The sample was further distributed into an equal number of students in two groups. Some topics were selected from the grade-IX mathematics textbook. The selected mathematical topics were taught to the control group by lecture method whereas computer simulations were used for teaching mathematical concepts to the experimental group. Data analysis showed that in the posttest, the experimental group performed better than the control group at a 0.05 level of significance. The scores of the retention test of the experimental group were also found better than the control group. It is recommended to include computer simulations in the teaching-learning process for better comprehension of abstract concepts of mathematics.
\end{abstract}

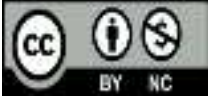

Keywords: Achievement, Mathematical Concepts, Retention, Simulations

\section{Introduction}

The world is rapidly changing due to new requirements and the latest trends. The use of technology has been increased in all aspects of life. The daily operations of life have also been digitalized. Technology has modified our ways of thinking, teaching, and learning processes. Nowadays latest technologies are providing diverse facilitates and learning opportunities. Science and technology brought new insight into the field of education. The learner of the $21^{\text {st }}$ century wants to learn through digital media and the latest technologies. In this era, no one can deny the significance of information and communication technologies. The progress of the twenty-first century brought many changes in the societies of

${ }^{1}$ Assistant Professor, EPPSL Department, Allama Iqbal Open University, Islamabad, Email: farkhunda.rasheed@aiou.edu.pk

${ }^{2}$ Assistant Director (Academics), Federal Government Educational Institutions (C/G), Directorate, Rawalpindi Email: drtariqjaved@miu.edu.pk 
the world including the standards of educational institutes and education. Therefore, nowadays, information and communication technology are being used in education. A simulation is considered a powerful effective technique used for concept clarification and decision-making through virtual representation based on reality. Computer simulations are most frequently used for space training, medical fields, and now in education. Its rate of usage is different in developed countries as compared to developing or under developing countries. The latest technologies are being used in industry, commerce, business (Riley, Cadottee, Mac Guire, 2016), medical, pharmacy (Vyas, Bray \& Wilson, 2013), agriculture, engineering (Koh, Tan \& Fang, 2010), and in education. As mathematics is the basis of all sciences. Therefore, to make improved learning, computer simulations are being used all over the world for learning mathematics and science subjects at elementary, secondary, and higher levels (Crocco, Offenholly, Hernandez, 2016).

A well-structured computer-based mathematical teaching can enhance information processing. Since $90 \%$ of learning happens by doing therefore visual technologies are a better source for understanding the concepts (Simsek, 2002; Demirel, 2004; Türel, 2010, 2011). Moreover, visual technologies along with audio, animations, and simulation effectively influence student's academic achievement. All over the world, efforts have been made to keep the institution modern and up to date. Internationally there is the greatest challenge to enhance teaching and learning within schools (Aldrich, 2004, 2005 quoted by Balasubramanian \& Wilson, 2006).

For effective computer-based instruction, facilities like the latest computers, good internet connectivity, and computer support are essential (Brekke \& Hogstad, 2010). However, for effective use of interactive simulations, sufficient time is required to test and use it in pedagogy. Therefore, a careful investigation into simulations is required before implementing them in the pedagogy. Similarly, with the use of technology, student's learning can be strengthened and pedagogy can be improved (Dede, 2000). Moreover, in the teaching-learning process, technology can be used effectively as a cognitive tool (Bransford, Brown \& Cocking, 2000, Baek \& Kim, 2008). Simulations are also helpful for the better understanding of scientific concepts and the development of positive attitudes toward science. Moreover, simulations are also helpful for the positive changes in the perceptions and attitudes toward scientists (Chen \& Howard, 2010). Literature also provides evidence that computer-assisted teaching more effective as compared to the traditional method for removing 
misconceptions of students (Gürbüz \& Birgin, 2012). With the help of simulations, student's active learning promotes, as simulations provide more concrete representation, encourage co-operation among students, give prompt feedback, and facilitate visual and kinesthetic styles of learning (McGrath, 2008). In short, computer simulations are found effective and are being used for removing misconceptions and improving retention of mathematical concepts around the globe.

\subsection{Objectives of the Study}

1. To find the effectiveness of simulation-based teaching.

2. To compare the retention of the control group with the experimental group.

\subsection{Hypotheses of the Study}

$\mathrm{H}_{\mathrm{o} 1}$ : There is no significant difference in the academic achievement of students with and without simulation-based teaching.

$\mathrm{H}_{\mathrm{o} 2}$ : There is no significant difference in the retention of the control group with the experimental group.

\subsection{Significance of the Study}

In mathematics teaching and learning, there is great significance of drill, practice, and activities. Over time, there is a change in the mode of practice and activity work. There is most of the science and mathematical concepts are abstract. There is a need to visualize those concepts. Nowadays, new and modern instruments are being used in science and mathematics teaching. Simulations not only create interest among learners but also help them to visualize abstract phenomena. The findings of the study will be helpful to teachers so that they can understand the significance of simulations for teaching and learning. This will help teachers to adopt new techniques which will make their teaching interesting for students and learners will be able to better grasp mathematical concepts. The simulation will also help the learners to retain their knowledge for later usage. This study will encourage mathematics teachers to make their instruction more interesting, useful, and according to student's needs as today's learners like to learn with the use of technology.

\subsection{Delimitations of the Study}

This study was delimited to only female students of class $9^{\text {th }}$ and the content of mathematics was taught. 


\section{Literature Review}

Technology is facilitating the instructors to use the innovative methods of teaching mathematics as per the needs of the students of this digital era. With the emergence of mobile technology, sophisticated apps are now placed in a remarkable position in society, which provides opportunities to learn in real-time. For this purpose, simulations are used to teach fractions in mathematics (Huber et al, 2016) and the concept of geometrical figures can be made easy for students (Steen, Brooks, \& Lyon, 2006). An artificial mechanism to operate in a realworld process through digital tools is known as simulation. Model of behavior is utilized for the deep understanding of learning concepts. White and Ingalls (2009) have defined simulations as "simulation is experimentation with a model. The behavior of the model imitates some salient aspect of the behavior of the system under study and the user experiments with the model to infer this behavior". Simulations are considered emerging and motivational tools of learning for secondary school students (Lovato \& Waxman, 2016).

Simulations provide an opportunity for students to create their learning environment for mathematics, which promotes intrinsic motivation among learners at the secondary level (Akinsola \& Animasahun, 2007). Simulations are being used to teach mathematics at the secondary level for a long time (Burns \& Hamm, 2011) and, recently simulations are applied to teach science education (Zacharia \& Dejong, 2014; Zacharia, 2007). It has been observed that simple learning design models using simulations are effective as compared to different models of simulations towards enhancement of knowledge and skills, therefore, learning objectives can be achieved from both individual and group tasking (Tako, Tisoptsias \& Robinson, 2020). Simulations have an important role in scientific reasoning and are considered as the powerful tool for science learning that bears the potential of understanding depends upon modeling. A mathematical calculation tool is utilized to develop optimum designs for simulation based on modeling assumptions which can be used to analyze and predict data (Wiechert, 2002) at deeper levels leading to a high retention rate (Falloon, 2019) provide the details of using a variety of simulations in early grades for learning of science concepts. Higher-order capabilities like reflective and critical thinking may be created through simulations, which help the students towards abstract clarification.

The use of simulations in the mathematics teaching-learning process is increasing day by day due to effectiveness towards clarification of complex ideas and at the same time simulations change thought processes with fast visual 
communication. Now simulations and future learning of science depend upon each other (Clark et al., 2009). Digital simulation models are used in both abstract and concrete situations which facilitate the learners to explore or modify the learning parameters under the influence of the suggested digital model to obtain learning objectives in a real-time environment. Targeted simulations (userfriendly simulations) are also widely used in science education by science teachers and students with a focus on time minimization with the achievement of learning objectives (Clark et al., 2009). The advantage of targeted simulations is to explore innovative learning in a short time and keep the learners on right track due to motivation and focus on specific tasks and communication, therefore, targeted simulations are recommended in science education due to flexible and interactive approaches (Clark et al., 2009). The instructional use of digital simulations serves as a scaffold for learning abstract concepts such as genetic irrespective of learners' gender and ability levels (Akhigbe \& Ogufere, 2020). The traditional ways of teaching result in different learning problems for students. Akinsola and Animasahun (2007) have stated that students face problems in learning mathematics due to the traditional way of teaching because traditional methods of teaching are carried out during the teaching-learning process. Teachers at the secondary level should focus on the teaching ways through which workload can be minimized to achieve mathematics learning objectives, this can be made easy through the use and application of simulations for mathematical concept clarification at the secondary level. So in this way teachers can develop a deep understanding of mathematics. In the same context, Lye, Wee, \& Ong (2012) have investigated the use of simulations with implementing a guided inquiry approach whereas the learners from secondary school manipulated energy simulations. The author concluded that the use of simulations for secondary students can improve students' understanding of the topic however, the energy simulation that was used in this research was designed for elementary classrooms.

During learning in a simulated environment, students are exposed to an inductive learning mode, in which students are the "active agent in the process of knowledge acquisition" and such circumstances provided the learners to respond to the questions, design investigations, and evaluate their learning. It has been considered that simulations (digital) are the replacement of the traditional mode of learning in science education. Simulation games are beneficial for learners which provides a motivational learning environment that reflects in the form of mathematical attitude and academic achievement in mathematics at the secondary level (Akinsola \& Animasahun, 2007). According to Sulaiman, Baba 
and Bulama (2016), academic achievement in mathematics is increased through the use of simulations in the learning environment. The combination of lecture method and simulation techniques are more effective as compared to traditional methods of teaching in mathematics. Gimba, Falode and Bashir (2015) have argued that the level of retention in mathematics at the secondary level can be increased with the help of digital simulations, which provide an effective learning environment to learners.

It was found that instruction of arithmetic progression with the aid of computer simulations is effective and learners retained the mathematical concepts for a longer period. Therefore simulations can be used along with the traditional lecture method (Gimba, Falode \& Bashir, 2015). It was found that simulation games led to enhance the level of mathematical attitude of learners (Akinsola \& Animasahun, 2007). There are different uses of simulations in the teaching-learning process. Akhigbe and Ogufere (2020) have indicated that simulations can be utilized as a pedagogical tool for maximizing the cognition of difficult and abstract concepts in biology. Teachers can convert the negative or passive attitude of mathematics learning to a positive or active attitude through the proper use of simulations at the secondary level (Akinsola \& Animasahun, 2007).

\subsection{Research Design}

\section{Research Methodology}

For this study, a pretest-posttest equivalent group experimental design was applied. Two equivalent groups were formulated through random sampling.

\subsection{Population of the Study}

The population of this study comprised of all science students studying mathematics at the secondary level in an urban area of Rawalpindi.

\subsection{Sample and Sampling Technique}

A sample of 100 students was drawn from Grade IX female students of secondary level. It was further distributed into two equal groups; one group was considered as the control group while the other group was considered as the experimental group. There were 50 students in each group. In this study, those mathematical concepts were selected which according to students were found more difficult to understand. The following mathematics topics were taught from the textbook of $9^{\text {th }}$-grade mathematics:

(a) Fundamental laws of Algebra

(b) Completing the square

(c) Factoring a quadratic trinomial 


\subsection{Intervention}

(d) Plotting points on the coordinate system

Four lessons were taught to both groups. Computer simulations were used as an intervention for the experimental group whereas there was no intervention for the control group. Internet connectivity was used to run simulations and a projector was used for full-scale display to the experimental group. The experimental group was taught in the computer lab for six weeks. Students had the opportunity to run the simulations by changing different variables. The control group was treated with the conventional method, using the lecture method. After six weeks, both groups were assessed by post-test. The retention test was also conducted for both groups after eight weeks. One of the screenshots is as follows:

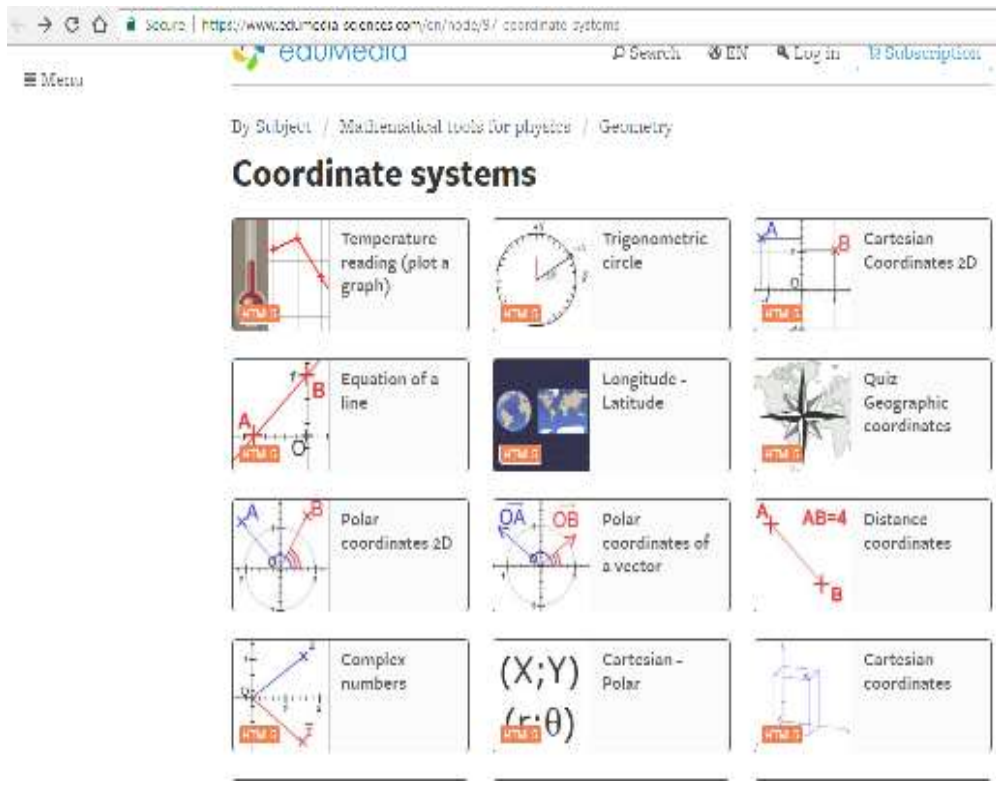

Figure 1 (source: https://www.edumedia-sciences.com/en/node/97-coordinatesystems)

Pretest and posttest were based on MCQs format. The detail is as follows:

\subsection{Instrumentation}

The initial tests were consisted of 35 MCQs in each test. The difficulty and discriminatory index of both the tests were measured. After pilot testing, 
item analysis was done to determine item difficulty level and discrimination index. The items with difficulty level and discrimination index below and above the selected range were discarded and 20 -items were taken for the final selection of the tests. There were 40 marks for the pretest and posttest. However, due to the COVID-19 situation, the number of students reduced in classrooms, therefore, there were 10 items in the retention test. For the retention test, a parallel form test was constructed. Initially, there were 20 items in the test. After validation, 10 items were retained in the retention test. The total marks of the retention test were 20. The tests were based on the theoretical aspect from selected topics of Mathematics.

The content validity of the tests was found through experts i.e. four (04) senior mathematics teachers. Teaching experience of those mathematics teachers ranges (7-12) years. The reliability of the tests was found using the split-half method. The coefficient of the reliability (Cronbach's Alpha) was found 0.85.

\section{Data Analysis and Interpretation}

The data analysis and its interpretation are as follows:

Table 4.1

Range of Scores

\begin{tabular}{|c|c|c|c|c|c|c|}
\hline Groups & $\mathrm{n}$ & Range & Min & Max & $\bar{M}$ & SD \\
\hline $\begin{array}{l}\text { Pre-test control group } \\
\end{array}$ & 50 & 12.00 & 14.00 & 26.00 & 21.18 & 2.631 \\
\hline Post-test control group & 50 & 10.00 & 15.00 & 25.00 & 21.54 & 2.331 \\
\hline $\begin{array}{l}\text { Pre-test Experimental } \\
\text { group }\end{array}$ & 50 & 11.00 & 15.00 & 26.00 & 21.10 & 2.597 \\
\hline $\begin{array}{l}\text { Post-test Experimental } \\
\text { group }\end{array}$ & 50 & 4.00 & 26.00 & 30.00 & 28.10 & 1.147 \\
\hline
\end{tabular}

Table 4.1 shows a range of scores of pretest and post-tests of the control and experimental group. It shows variation in a range of scores.

Table 4.2

Scores of Experimental and Control Group in Pre-test

\begin{tabular}{lccccc}
\hline Pretest group & $\mathrm{n}$ & $\mathrm{M}$ & $\mathrm{SD}$ & $\mathrm{t}-\mathrm{cal}$ & $\mathrm{p}$ \\
\hline Control & 50 & 21.800 & 2.63 & 0.531 & .598 \\
Experimental & 50 & 21.100 & 2.59 & &
\end{tabular}

Table 4.2 shows that a p-value of 0.598 is not significant at the 0.05 level. Since both groups were created based upon their previous scores. It was assured that both groups must contain students of the same abilities as compared to each other. Hence, in the pre-test, the scores of both groups were almost the 
same. It shows that both the groups were equal in terms of scores before the experiment.

Table 4.3

Sores of Experimental Group and Control Group in Post-test

\begin{tabular}{lccccc}
\hline Posttest group & $\mathrm{n}$ & $\mathrm{M}$ & $\mathrm{SD}$ & $\mathrm{t}-\mathrm{cal}$ & $\mathrm{p}$ \\
\hline Control & 50 & 21.54 & 2.33 & -19.74 & .000 \\
Experimental & 50 & 28.100 & 1.14 & & \\
\hline
\end{tabular}

Table 4.3 shows that the $p$-value is less than the 0.05 level of significance. In the post-test, scores of both groups were different from each other. Whereas, scores of the experimental group were significantly higher than the control group. Therefore, the first hypothesis is rejected and the alternate hypothesis is accepted that there is a significant difference in the mean scores when taught with simulations.

Table 4.4

Sores of Experimental Group in pre-test and post-test

\begin{tabular}{lccccc}
\hline Test group & $\mathrm{n}$ & $\mathrm{M}$ & $\mathrm{SD}$ & $\mathrm{t}-\mathrm{cal}$ & $\mathrm{p}$ \\
\hline $\begin{array}{l}\text { Experimental } \\
\text { Group Pre-test }\end{array}$ & 50 & 21.100 & 2.59 & -6.144 & .000 \\
$\begin{array}{l}\text { Experimental } \\
\text { Group Post-test }\end{array}$ & 50 & 28.100 & 1.14 & & \\
\hline
\end{tabular}

Table 4.4 shows that when the gain in scores of the only experimental group was compared with its pre-test and post-test, a significant difference in the mean scores of pretest and posttest was found. This shows that simulations had a great impact on the mean score achievement of students.

Table 4.5

Scores of Control Group in pre-test and post-test

\begin{tabular}{lccccc}
\hline Test group & $\mathrm{n}$ & $\mathrm{M}$ & $\mathrm{SD}$ & $\mathrm{t}-\mathrm{cal}$ & $\mathrm{p}$ \\
\hline $\begin{array}{c}\text { Control Group } \\
\text { Pre-test }\end{array}$ & 50 & 21.1800 & 2.63 & -1.498 & .141 \\
$\begin{array}{c}\text { Control Group } \\
\text { Post-test }\end{array}$ & 50 & 21.54 & 2.33 & & \\
\hline
\end{tabular}

Table 4.5 shows a comparison of pretest scores and post-test scores of the control group. Although on post-test, the control group obtained slightly greater scores than pretest, however, this difference is not significant. As the 
control group did not receive any intervention, therefore the control group showed no significant difference in the mean scores in the posttest.

Table 4.6

Retention of Experimental and Control Group

\begin{tabular}{lcccccc}
\hline \multicolumn{1}{c}{ Group } & $\mathrm{n}$ & $\mathrm{M}$ & $\mathrm{SD}$ & SE Mean & $\mathrm{t}-\mathrm{cal}$ & $\mathrm{p}$ \\
\hline Experimental & 18 & 15.388 & 1.786 & 0.4211 & 9.384 & 0.000 \\
Control & 18 & 10.444 & 1.503 & 0.3544 & & \\
\hline$d f=17$ & & & & & &
\end{tabular}

The retention test was taken after eight weeks of the experiment/intervention of the study. Due to COVID-19, limited students were available. Therefore, only eighteen students could be available from each group. There were 10 items in the retention test. The total score of retention tests was 20. Table 4.6 shows a significant difference between the mean scores of both groups in the retention test. It shows that although the experiment was finished when students were asked to solve questions of the concepts which were developed on the same pattern and from the same content which was used during the study. It was found that the scores of students of experimental students were higher than the scores of students of the control group. It provided evidence that simulation-based instruction is also helpful for the retention of concepts. It also shows that the second hypothesis is rejected as simulations affected the retention of concepts.

\section{Discussion and Conclusion}

Mathematics is being taught as a compulsory subject up to secondary level. As it is being used in daily life and different disciplines in one way or other. There are numerous ways through which mathematics teaching can be made more interesting, engaging, and interesting for the learners. However, in this era of technology, simulations are being helpful to teach students. Today's learners are technologically oriented and want to visualize concepts being taught to them. Computer simulations provide an opportunity for students for understanding abstract concepts. Simulations provide an interactive learning environment and immediate feedback for learning. Due to the design and style of simulations, learners take more interest in learning. In this study, performance of the experimental group when taught with simulations was found better than the control group. It may be due to the reason that with the help of simulations, the students might have more understanding of mathematical concepts than mere lecture method. The findings of the study are in line with Ishaq, Latunde, Ogwumu, Mustapha, and Ajinuhi (2019), where researchers found that the use of simulations is helpful for the enhancement of achievement 
and attitude towards mathematics. Akinsola and Animasahun (2007) indicated that a simulation-game environment helps improve positive attitudes towards mathematics and achievement in mathematics. Moreover, simulations help to sustain and motivate student's interest in learning mathematics. Science learning demands spatial thinking skills. Simulations facilitate students learning of science concepts (Çigrik \& Ergül, 2009; Stern, Barnea \& Shauli, 2008). This study also aimed to find the effect of simulation on the retention of students. The intervention of simulations was found helpful to retain mathematical knowledge even after few weeks of instruction. This finding is in line with Olalekan and Oladele (2016) and Tayo (2012) that with the help of computers the retention ability of students enhances. This might be due to the reason as described by Tayo (2012) that due to motion, information is stored in long-term memory therefore retention rate increases. This finding is also supported by the fact provided by Mayer and Anderson (1991) as quoted by Lin (2011) that dualcoding theory supports retention in long-term memory by combining visual and verbal cues. Moreover, by adding animations and narrations, dual-coding is further supported. In simulations, students can manipulate the variables and observe the phenomenon from different perspectives. Therefore, after many days of simulation-based instruction, the students retained the obtained knowledge. In this study, the use of simulations helped to retain the mathematical concepts. This finding is in line with Rendel, Morris, Wetzel, and Whitehill (1992) as quoted by Akinsola and Animasahun (2007) where researchers claimed that "the positive results obtained for retention over time favors the use of simulation /games". Hence, simulation-based instruction yields not only better results in terms of scores but also helps to retain the obtained knowledge especially the knowledge of abstract concepts.

The secondary school stage is the decisive stage of the students, where learners decide the field of further studies. It is observed and results of the board examination show that most of the students get less scores in mathematics. That is why most of the students opt for such courses which do not have mathematics in combination with it. The study of mathematics carries several abstract concepts to comprehend. Teachers can use digital technologies to assist their teaching and make their teaching easy and interesting for students. In this study, simulations were used, and it was found that the learning of students had been improved. Students showed greater opportunity to manipulate variables and their impact on the result of mathematical concepts. It also provided them interest and zeal to learn. Therefore, it is concluded that computer simulationbased mathematical teaching is significantly effective than the conventional 
method of teaching. Students' academic achievement can be improved by using computer simulation-based mathematical teaching. Simulations also help the learners to retain mathematical concepts easily.

\section{Recommendations}

Based on findings, the following recommendations are being put forward:

1. Simulations may be used at the secondary school level to teach mathematics concepts so that the academic achievement of students can be improved.

2. Computer simulation-based teaching methods may be applied for the improvement of educational standards and quality of education.

3. Mathematics' labs must be furnished or developed with the latest technologies including computers in all learning centers.

4. The preparation of simulation is a difficult task, therefore ready-to-use simulations may be used/purchased.

5. Higher authorities must facilitate, and train teachers regarding computer simulation software and must be used for teaching other science subjects.

\section{References}

Akinsola, M.K., Animasahun, I.A. (2007). The effect of simulation-games environment on students' achievement in and attitudes to mathematics in secondary schools, The Turkish Online Journal of Educational Technology, 6(3), 113-119.

Akhigbe, J. N., Ogufere, J. A. (2020). Effect of computer simulation instructional strategy on students' attitude and academic achievement in Genetics, KIU Journal of Social Sciences, 5(4), 305-315.

Aldrich, C. (2004). Simulations and the future of learning: An innovative (and perhaps revolutionary) approach to e-learning. San Francisco: Pfeiffer.

Aldrich, C. (2005). Learning by doing: A comprehensive guide to simulations, computer games, and pedagogy in e-learning and other educational experiences. San Francisco: Pfeiffer.

Baek, Y., Jung, J., \& Kim, B. (2008). What makes teachers use technology in the classroom? Exploring the factors affecting facilitation of technology with a Korean sample. Computers \& Education, 50(1), 224-234. 
Balasubramanian, N., \& Wilson, B. G. (2006). Games and Simulations. Paper presented at the Society for information technology and teacher education international conference.

Bransford, J. D., Brown, A. L., \& Cocking, R. R. (2000). How people learn? Washington, DC: National Academy Press.

Brekke, M., \& Hogstad, P. H. (2010). New teaching methods-Using computer technology in physics, mathematics, and computer science. International Journal of Digital Society, 1(1), 17-24.

Burns, B., \& Hamm, E. (2011). A comparison of concrete and virtual manipulative use in third and fourth grade Mathematics. School Science and Mathematics, 111(6), 256- 261.

Chen, C. H., \& Howard, B. (2010).Effect of live simulation on middle school students' attitudes and learning toward science. Journal of Educational Technology \& Society, 13(1), 133-139.

Çı̆̆rık, E., \& Ergül, R. (2009). The investigation of the effect of simulation-based teaching on student achievement and attitude in electrostatic induction. Procedia-Social and Behavioral Sciences, 1(1), 2470-2474.

Clark, D. B., Nelson, B. P. Sengupta, D’Angelo, C. M. (2009). Rethinking science learning through digital games and simulations: genres, examples, and evidence. Proceedings of The National Academies Board on Science Education Workshop on Learning Science: Computer Games, Simulations, and Education, 36-41.

Crocco, F., Offenholley, K., \& Hernandez, C. (2016).A Proof-of-Concept Study of Game-Based Learning in Higher Education. Simulation \& Gaming, 47(4), 403-422.

Dede, C. (2000). Emerging influences of information technology on the school curriculum. Journal of Curriculum Studies, 32(2), 281-303.

Demirel, Y. (2004). Effective teaching and active learning of engineering courses with workbook strategy. Proceedings of the 2004 American 
Society for Engineering Education Annual Conference \& Exposition, 9.505.1- 9.505.14.

Falloon, G. (2019). Using simulations to teach young students science concepts: an experiential learning theoretical analysis. Computers, and Education, $135,138-159$.

Gimba, R. W., Falode, O. C., \& Bashir, A. U. (2015). Effect of computer simulation instructional package on senior secondary school mathematics students' retention in arithmetic progression in lavun local government area of Niger State, Nigeria, The African Symposium: An online Journal of the African Educational Research Network, 15(1), 20-24.

Gürbüz, R., \& Birgin, O. (2012). The effect of computer-assisted teaching on remedying misconceptions: The case of the subject "probability". Computers \& Education, 58(3), 931-941.

Ishaq, A.A., Latunde, T., Ogwumu, D., Mustapha, A.M., \& Ajinuhi, J.O. (2019). Impacts of simulation games on teaching and learning Mathematics. Journal of Science Technology and Education, 7(4), 129-134.

Huber, B., Tarasuik, J., Antoniou, M., Garret, C., Bowe, S., Kaufman, J., \& Swinburne Babylab Team. (2016). Young children's transfer of learning from a touch screen device. Computers in Human Behaviour, 56, 56-64.

Koh, C., Tan, H. S., Tan, K. C., Fang, L., Fong, F. M., Kan, D., . . \& Wee, M. L. (2010). Investigating the effect of 3D simulation-based learning on the motivation and performance of engineering students. Journal of Engineering Education, 99(3), 237-251.

Lin, H. (2011). Facilitating learning from animated instruction: effectiveness of questions and feedback as attention directing strategies. Educational Technology \& Society, 14(2), 31-42.

Lovato, S., \& Waxman, S. (2016). Young children learning from touch screens: Taking a wider view. Frontiers in Psychology, 7, 1- 6. 
Lye, S. Y., Wee, L. K., \& Ong, Y. C. (2012). Open source energy simulation for elementary school. Proceedings of the $20^{\text {th }}$ International Conference on Computers in Education, ICCE 2012, 280-84.

Mayer, R. E., \& Anderson, R.B. (1991). Animations need narrations: an experimental test of a dual-coding hypothesis. J. Educ. Psychol. 83, 484490.

McGrath, D, Savage, C. and Williamson, M., Wegener, M and McIntyre, T (2008). Teaching special relativity using virtual reality. Proceedings of The Australian Conference on Science and Mathematics Education (formerly UniServe Science Conference)

Olalekan, A. A., \& Oladele, O. (2016). Effects of computer simulation instructional strategy on biology students' academic achievement in DNA replication and transcription. Asian Journal of Educational Research, 4(2),16-24.

Riley Jr, R. A., Cadotte, E. R., Bonney, L., \& MacGuire, C. (2013).Using a business simulation to enhance accounting education. Issues in Accounting Education, 28(4), 801-822.

Şimsek, N. (2002). BIG G16 learning modality inventory. Journal of Educational Sciences \& Practices, 1(1), 34-47.

Steen, K., Brooks, D., \& Lyon, T. (2006). The impact of virtual manipulative on first-grade geometry instruction and learning. Journal of Computers in Mathematics and Science Teaching, 25(4), 373-391.

Stern, L., Barnea, N., \& Shauli, S. (2008). The effect of a computerized simulation on middle school student's understanding of the kinetic molecular theory. Journal of Science Education and Technology, 17(4), 305-315.

Sulaiman, B., Baba, I. M., \& Bulama, B. I. (2016). Effect of simulation techniques and lecture method on students' academic performance in mafoni day secondary school Maiduguri, Borno State, Nigeria. Journal of Education and Practice, 7(23), 113-17. 
Tayo, D. (2012). Effects of the animated agricultural package on attitude and performance of JSS Students in South Western Area, Nigeria. MJSS Journal, 425-230.

Tako, A. A., Tisptsias, N., Robinson, S. (2020). Can we learn from simplified simulation models? An experimental study on user learning, Journal of Simulation, 14(2), 130-144.

Türel, Y. K. (2010). Developing teachers' utilization of interactive whiteboards. In D. Gibson \& B. Dodge (Eds.). Proceedings of Society for Information Technology \& Teacher Education International Conference 2010, Chesapeake, VA: AACE, 3049-3054.

Türel, Y. K. (2011). An interactive whiteboard student survey: Development, validity, and reliability. Computers \& Education, 57, 2441-2450.

Vyas, D., Bray, B. S., \& Wilson, M. N. (2013). Use of simulation-based teaching methodologies in US colleges and schools of pharmacy. American Journal of Pharmaceutical Education, 77(3), 53-61.

Wiechert, W. (2002). Modeling and Simulation: tools for metabolic engineering, Journal of Biotechnology, 94(1), 37-63.

White, K. P. \& Ingalls, R. G. (2009). Introduction to simulation. Rossetti, M. D., Hill, R.R., Johansson, B., Dunkin, A., \& Ingalls, R. G.(eds.). Proceedings of the 2009 Winter Simulation Conference, 12-23.

Zacharia, Z. (2007). Comparing and combining real and virtual experimentation: An effort to enhance students' conceptual understanding of electric circuits. Journal of Computer-Assisted Learning, 23, 120-132.

Zacharia, Z., \& de Jong, T. (2014). The effects on students' conceptual understanding of electrical circuits of introducing virtual manipulative within a physical manipulative-oriented curriculum. Cognition and Instruction, 32(2), 101-158. 
International Journal of Innovation in Teaching and Learning (IJITL)

Volume VII- Issue II (December 2021)

\section{Citation of this Article:}

Choudhary, F. R., \& Javed, T. (2021). Use of Computer Simulations for the Understanding and Retention of Mathematical Concepts. International Journal of Innovation in Teaching and Learning (IJITL), 7(2), 70-86. 